\title{
Current US neurosurgical resident involvement, interest, and barriers in global neurosurgery
}

\author{
Paige Lundy, MD, Christopher Miller, MD, and Sarah Woodrow, MD \\ Department of Neurological Surgery, University of Kansas, Kansas City, Kansas
}

OBJECTIVE It is estimated that nearly 47 million preventable deaths occur annually due the current worldwide deficit in surgical care; subsequently, the World Health Organization resolved unanimously to endorse a decree to address this deficit. Neurosurgeons from industrialized nations can help address the needs of underserved regions. Exposure during training is critical for young neurosurgeons to gain experience in international work and to cultivate career-long interest. Here, the authors explore the opinions of current residents and interest in global neurosurgery as well as the current state of international involvement, opportunities, and barriers in North American residency training.

METHODS An internet-based questionnaire was developed using the authors' university's REDCap database and distributed to neurosurgical residents from US ACGME (Accreditation Council for Graduate Medical Education)-approved programs. Questions focused on the resident's program's involvement and logistics regarding international rotations and the resident's interest level in pursuing these opportunities.

RESULTS A 15\% response rate was obtained from a broad range of training locations. Twenty-nine percent of respondents reported that their residency program offered elective training opportunities in developing countries, and $7.6 \%$ reported having participated in these programs. This cohort unanimously felt that the international rotation was a beneficial experience and agreed that they would do it again. Of those who had not participated, $81.3 \%$ reported interest or strong interest in international rotations.

CONCLUSIONS The authors' results indicate that, despite a high level of desire for involvement in international rotations, there is limited opportunity for residents to become involved. Barriers such as funding and rotation approval were recognized. It is the authors' hope that governing organizations and residency programs will work to break down these barriers and help establish rotations for trainees to learn abroad and begin to join the cause of meeting global surgical needs. To meet overarching international neurosurgical needs, neurosurgeons of the future must be trained in global neurosurgery.

https://thejns.org/doi/abs/10.3171/2019.12.FOCUS19808

KEYWORDS global neurosurgery; residency training; international neurosurgery

I N 2015 The Lancet Commission on Global Surgery and the World Bank emphasized essential surgical care as a basic necessity for humankind. It is estimated that nearly 47 million preventable deaths occur annually due the current deficit in surgical care. Subsequently, the World Health Organization resolved unanimously to endorse a decree to address this deficit. ${ }^{5,16}$ It has been estimated that approximately 49,949 additional neurosurgeons are needed worldwide to meet the critically growing needs in surgical care. ${ }^{8,17}$ The global density of neurosurgeons is estimated to be 1 per 230,000 population. However, in low- and middle-income countries, the density is as low as 1 per 9 million population. ${ }^{17}$

Neurosurgeons from industrialized nations can help address the needs of underserved regions. However, the efforts of traveling neurosurgeons need to be consistent and longitudinal rather than "one-and-done" efforts. Ongoing training and development of programs with consistent support from the developed nations are critical to ultimately foster independence and enduring solutions to the surgical deficit. ${ }^{2,10,15,20}$ Exposure during training is critical for young neurosurgeons to gain experience in international work

ABBREVIATIONS ACGME = Accreditation Council for Graduate Medical Education; PGY = postgraduate year; RRC = residency review committee. SUBMITTED October 17, 2019. ACCEPTED December 16, 2019.

INCLUDE WHEN CITING DOI: 10.3171/2019.12.FOCUS19808. 
and to cultivate a career-long interest. ${ }^{2}$ Beyond the benefits for underserved regions, global health electives offer neurosurgical trainees the opportunity to expand their cultural awareness, increase their knowledge of medical cost, and refine their clinical decision-making skills. ${ }^{11,13,18,22}$ In turn, the residents who trained internationally will be better equipped to return to international sites and provide education to local providers throughout their career, thus allowing for a consistent and longitudinal workforce to address underserved populations.

The implementation or expansion of international educational programs in neurological surgery requires a strong resident interest and the availability of international work during residency training. Anecdotal experience has suggested that there is growing interest in this field, but many younger neurosurgeons report difficulty engaging in this activity. ${ }^{9}$ Therefore, a key step in developing an international educational infrastructure is to understand the current resident opinions and interest in global neurosurgery as well as the current state of international involvement, opportunities, and barriers in US residency training.

\section{Methods}

This study was reviewed and qualified for exempt status by the University of Kansas institutional review board.

An anonymous internet-based questionnaire was developed and distributed using our university's REDCap database. The survey was distributed to current neurosurgical residents at Accreditation Council for Graduate Medical Education (ACGME)-approved programs throughout the US, who were identified using the AANS database. Nonresponders were contacted a total of 4 times, and the survey was open from February 4, 2019, through March 18,2019 . Baseline demographic information regarding the respondent's residency program was collected and included region, number of residents, and number of faculty. No specific information was asked that could match a specific resident with their responses.

Questions focused on the residents' programs. The residents were asked about their involvement in international trips in binary (yes/no) fashion, onto which questions were built to expand based on the different responses (Fig. 1). Based on how the residents responded, the total number of questions ranged from 12 to 18 (Supplemental Resident Survey).

Questions regarding a resident's interest level in pursuing these opportunities were queried using a 5-point Likert scale, where 1 indicates strongly interested; 2 , interested; 3 , neither interested nor uninterested; 4, uninterested; and 5 , strongly uninterested. This scale was also used to assess a resident's willingness to pay out of pocket and use vacation time for international rotations.

Those who had participated in international trips were asked questions about their experience and the logistics of their rotation using a multiple-choice format in which multiple answers and type-in comments were allowed. These questions included information regarding funding, time allotment, and ACGME approval. They were also asked using a Likert scale if they felt the rotation was beneficial (1, strongly agree; 2 , agree; 3 , neither agree nor disagree; 4 , disagree; 5 , strongly disagree). They were asked in yes/no format if they would do another rotation in the future and if they planned to travel to serve internationally in the future. Space for additional comments was provided to fully explore responses. All data were analyzed with descriptive statistics using IBM SPSS (version 25, IBM Corp.).

\section{Results}

\section{Baseline Demographics}

A 15\% (210/1397) response rate was obtained from residents training in 88 different programs in locations representing every major region in the US. Data collected represented a broad range of programs with regard to size in terms of resident complement and number of attending staff (Table 1). Residents from all levels of training responded, with the most frequent responses coming from PGY (postgraduate year) 4 and 5 residents (82/210).

\section{Current Rotation Abroad Status}

Over half (123/210) of responding residents reported having a faculty member who traveled abroad to practice neurosurgery in developing countries. However, only $29 \%$ $(61 / 210)$ reported that their residency program offered elective training opportunities in developing countries.

Of the $29 \%$ of residents with established programs at their institutions, 26.2\% (16/61) reported participation in these programs. The majority of international rotation participants were PGY 4-6 residents. Locations visited represented a wide range of sites, including countries throughout Africa, Central America, and Asia. Sixteen respondents provided locations of rotations in an opencomment field on the survey. Some reported multiple locations, resulting in 28 reported locations. Thirty-nine percent $(11 / 28)$ of the locations were in low-income countries as defined by the 2019 World Bank classification system based on country economies. Fourteen percent (4/28) were located in similarly defined low- to middle-income countries. ${ }^{24}$

This cohort unanimously felt that the international rotation was a beneficial experience and agreed they would do it again; $93.8 \%(15 / 16)$ reported that they planned to travel abroad in the future to serve internationally. Additionally, in the open-response section, 2 residents reported using vacation time to participate in an international rotation, as their program did not offer one. Both endorsed the value of their experiences.

Of those residents who participated in their institution's established program, $37.5 \%$ (6/16) reported that their rotation was ACGME approved. Among residents whose institution offered a rotation but they did not participate, $20 \%$ (9/45) reported having ACGME-approved rotations available at their institutions.

The majority reported a desire for clinical and surgical experiences, which matched the electives most commonly offered. Residents also expressed a desire to learn more about health systems administration and local professional policy during their rotation.

\section{Resident Interest and Barriers}

For residents who have not yet participated, $81.3 \%$ 


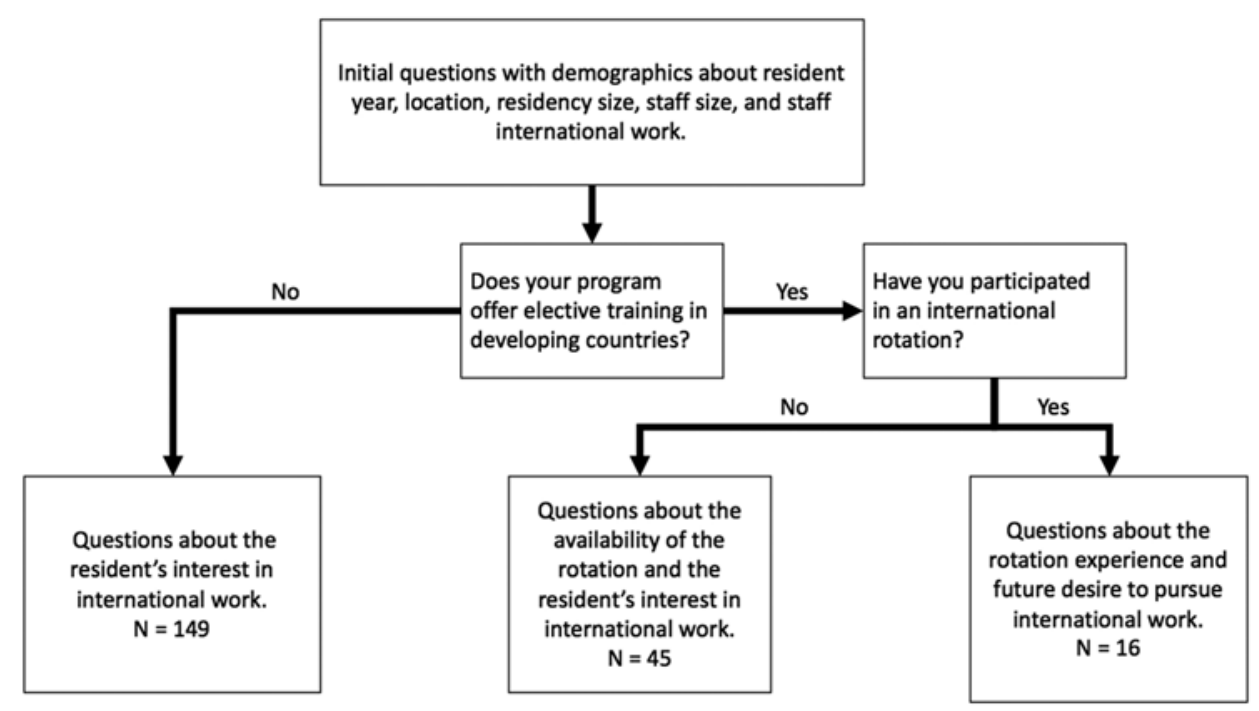

FIG. 1. Breakdown of the survey flow.

$(156 / 192)$ reported interest in international rotations (Fig. 2). Among those without offered rotations, 57\% (85/149) reported that they would be willing to use vacation time to complete an international rotation (Fig. 2). At institutions that offer rotations, $34.4 \%$ (21/61) reported that time was most often allotted during research rotations, while $21 \%$ (13/61) reported using vacation time to complete their rotation.

Regarding financial support, funding was most often provided by the resident's training department or through fundraising. If asked to pay out of pocket, 47.7\% (71/149) of residents responded that they were unwilling to do so (Fig. 3). Other sources of funding included grants and mission group funding.

\section{Discussion}

\section{Need for Surgical Care}

Five billion people lack access to safe surgical care. As a result, 140 million surgical cases go untreated, resulting in 47 million deaths due to preventable causes had there

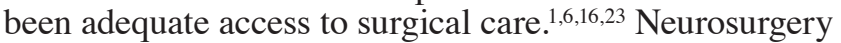
is key to meeting the deficits of surgical care, and head and spine trauma are a primary cause of mortality that require neurosurgical care. ${ }^{5}$ Meeting these needs will require work far beyond short-term humanitarian trips. The ultimate goal is to build programs with consistent support that foster local site independence and growth of a sustainable workforce abroad. In order to achieve these goals, part of the workforce of the future, today's current neurosurgical trainees, will need to become engaged and prepared to work on a global level.

\section{Interest and Value}

Addressing the neurosurgical needs of underserved nations is a complicated problem. Neurosurgeons traveling to nonindustrialized nations to function as educators, mentors, and laborers are one way to help the issue. However, for this to be effective, the aid must be consistent, and
TABLE 1. Demographic information of the 210 residents who replied to the survey

\begin{tabular}{|c|c|}
\hline & No. of Residents (\%) \\
\hline \multicolumn{2}{|c|}{ Current PGY Level } \\
\hline PGY 1 & $6(2.9)$ \\
\hline PGY 2 & $20(9.5)$ \\
\hline PGY 3 & $32(15.2)$ \\
\hline PGY 4 & $45(21.4)$ \\
\hline PGY 5 & $40(19)$ \\
\hline PGY 6 & $37(17.6)$ \\
\hline PGY 7 & $30(14.2)$ \\
\hline Total & 210 \\
\hline \multicolumn{2}{|c|}{ Current resident complement } \\
\hline $1-7$ & $20(9.5)$ \\
\hline $8-13$ & $66(31.4)$ \\
\hline $14-20$ & $90(42.9)$ \\
\hline$\geq 21$ & $34(16.2)$ \\
\hline Total & 210 \\
\hline \multicolumn{2}{|c|}{ Clinical faculty in program } \\
\hline $1-10$ & $69(32.9)$ \\
\hline $11-20$ & $109(51.9)$ \\
\hline$\geq 21$ & $32(15.2)$ \\
\hline \multicolumn{2}{|c|}{ Program location } \\
\hline Northeast & $54(25.7)$ \\
\hline Southeast & $34(16.2)$ \\
\hline South & $25(11.9)$ \\
\hline Midwest & $67(31.9)$ \\
\hline Northwest & $8(3.8)$ \\
\hline Southwest & $22(10.5)$ \\
\hline
\end{tabular}



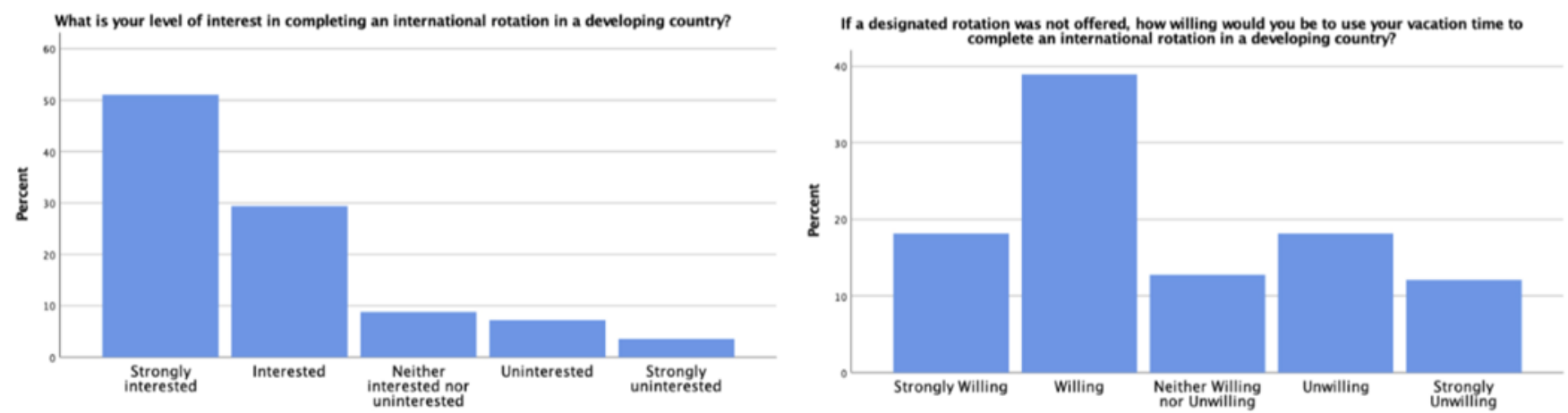

FIG. 2. Resident interest level in international rotations (left) and willingness to use vacation time for international rotations (right) $(n=210)$.

those providing the assistance must be keenly aware of the nuances of medical practice at the local sites. The earlier in a career this understanding can be developed, the greater the length of time in a career a given surgeon can be effective at a local site. ${ }^{7,11}$ There is great value in international experiences for building a foundation for future practice as well as enhancing current training. Furthermore, fostering an interest in global neurosurgery may help diversify an individual's practice into their career, thereby potentially mitigating career fatigue. For international training to start as early as residency, a basic but necessary component is resident interest.

Outside of neurosurgery, a national survey of surgical residents found that $73 \%$ would participate in an international rotation even if the cases they performed would not be counted for graduation requirements. ${ }^{19}$ Forty-two percent even reported a willingness to add an additional year to their training to solely focus on international work, possibly combined with research. ${ }^{19}$

A recent survey of pediatric neurosurgeons found that of those who had taught or performed neurosurgery in a developing country, $71 \%$ agreed that their international work improved their overall surgical practice, and 31\% agreed that international neurosurgical experiences should be a part of neurosurgical residency or fellowship. ${ }^{4}$

Neurosurgery residents join residents in other specialties with regard to interest and increasing involvement abroad. Our data agrees that among neurosurgical resi-

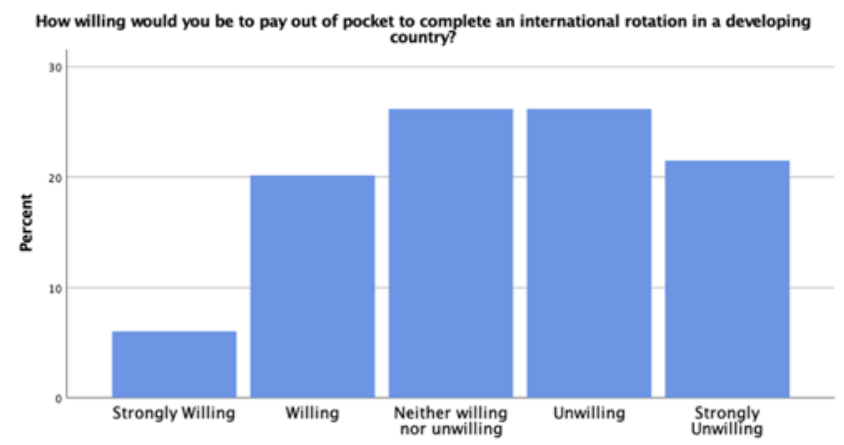

FIG. 3. Resident willingness to pay out of pocket for international rotations $(n=210)$. dents who have not yet participated, 81.3\% (156/192) are interested in pursuing these opportunities.

Our survey showed that neurosurgical residents who had participated unanimously felt that their global rotation was a beneficial experience and agreed they would do it again. They expanded on their feelings in open-text responses:

I think this would be a good educational experience to learn how problems are solved in settings that are extremely different than seen in the US. I feel like these types of experiences foster an innovative learning experience.

I believe this to be essential. It is very easy to overlook the privileges we have here in the US. Seeing other countries doesn't only help the resident provide healthcare to a community, it also helps residents see different pathologies.

I learned about a people, their culture, beliefs and the health adversities they face. Residency training in impoverished regions is very important to provide self-supportive health systems.

The data from this survey demonstrate a strong resident interest in international education and training. Furthermore, those residents who have participated in international opportunities overwhelmingly plan to continue international work in their career. In this way, international electives during residency represent a potent opportunity to develop an experienced international workforce that could provide long-term aid to underserved regions.

\section{Barriers}

Resident involvement provides an intriguing opportunity for advancement in international work; however, there are a number of barriers to their involvement. The barriers are multimodal, including home residency logistics, funding, accreditation board approval, and ethical implications. ${ }^{7,12,14,21,22}$ Our survey results demonstrated that there are barriers regarding funding and ACGME approval. A high percentage of residents (47.7\% [71/149]) responded that they were unwilling to pay out of pocket for international rotations.

The AANS offers scholarships for international providers seeking the opportunity to observe in the US as well as money toward a fellowship focusing on international education and training to already developed countries. 
However, no easily discoverable scholarships or grants are offered specifically for neurosurgical global education and training.

A few universities offer special funding for those interested in global surgery as well as larger organizations that do not specifically focus on one specialty but global surgery as a whole (e.g., The Paul Farmer Global Surgery Fellowship). ${ }^{11}$

Most surgical residency review committees (RRCs) do not recognize time spent abroad toward clinical training or allow for procedures to count toward accreditation requirements. A call has been made for accreditation organizations to develop core competencies and training guidelines with regard to international rotations in order to work toward residents receiving guidance and recognition for time spent aboard?

Currently, neurosurgery approval in the US requires full supervision by a core faculty physician, a minimum rotation length of 1 month, and demonstration of an ongoing relationship with the global site. These requirements are not within the means of many neurosurgical training sites. ACGME-approved rotations appear to be uncommon among neurosurgical training sites. Of those residents who had available rotations, only $24.6 \%(15 / 61)$ reported that they were ACGME approved. Developing a rotation outside of ACGME regulations creates a workaround to the barrier of approval, but it leaves residents vulnerable to international electives with low educational value and safety.

Understanding and addressing these barriers is important not only for resident international work but also to help the neurosurgeons who continue to travel throughout their career. Open comments further elaborated on frustrations with these barriers:

There is a strong desire among residents for international rotations but we are hampered by $\mathrm{RRC}$ requirements in many cases. If a policy could be outlined by the RRC for these rotations (i.e., have them count toward clinical or research time) this would be most helpful.

One of the most important things I did during my training. Wish I could have done more ... despite the fact that I did over 100 cases internationally during my residency. I had an interest, and so I sought out these opportunities. My department was supportive. However, I also paid out of pocket, and used my own vacation time for some of these experiences.

It was incredibly challenging to set up and organize this elective despite the fact that my faculty travel to international locations frequently but do not allow opportunities for residents to participate with them.

I took vacation time during my research year to do an international rotation. While my department was supportive of me, there was no direct support or help in setting up the rotation If given the opportunity, I would love to do more, and think it is an invaluable experience for all levels of residents.

Prior surveys of internationally traveling surgeons have recognized and discussed barriers. Respondents felt that involvement would be significantly easier had they been exposed to global surgery during their training. ${ }^{9}$ They recognized that current structural limitations exist on how training programs are incentivized to involve residents in these programs, despite their immense value.

\section{Ethics Concerns}

The ethical implications of global outreach should be considered with any international effort. Prior publications have discussed ethics concerns regarding placing residents in unsafe or ethically compromising situations or asking residents to function above their current training or level of comfort. ${ }^{3}$ First-time exposure to low- and low-middle-income countries must also be considered, as residents may benefit from preparation and counseling prior to rotations. Through the open-comment portion of our survey, residents discussed other ethical issues, including pitfalls and the responsibility of global neurosurgical outreach:

I don't believe that programs emphasize the ethical considerations at stake when planning medical missions to other countries (esp. developing nations). Many seem to be motivated by personal gain (i.e., vacation, heroism). Most developing nations don't need a visiting surgeon but rather need resources, training opportunities for local providers, and creative solutions to healthcare delivery barriers.

Fostering and developing an intimate understanding of ethics concerns during residency is crucial for creating an effective generation of global neurosurgeons.

\section{Limitations}

We recognize that a respondent bias may be present in our survey data. Those who are interested in or who have participated in international rotations would be more likely to respond to a survey on this topic. With regard to knowledge of the exact logistics (e.g., ACGME approval, funding), those who had actually participated in a rotation would likely have more accurate knowledge of approval status and exact funding sources. Thus, the results from nonparticipants may be skewed due to lack of detailed understanding. Although our response rate may seem small at $15 \%$, in general a $10 \%-15 \%$ response rate for external surveys is considered average, and, given the busy schedules of neurosurgical residents, we feel that our response rate was adequate. We also feel that our data represented a broad range of geographic regions and programs.

\section{Conclusions}

Our results indicate that, despite a high level of desire for involvement in international rotations, there is limited opportunity for residents to become involved. Barriers such as funding and rotation approval are recognized. Our hope is that governing organizations, foundations (such as FIENS [Foundation for International Education in Neurosurgery), and residency programs will work to break down these barriers in order to help establish rotations for trainees to learn abroad and begin to join the cause of meeting global surgical needs. We propose the possibility of a future centralized program or credentialing process that would streamline global education and training as well as promote and manage the development of travel grants and scholarships. To meet overarching international neurosurgical needs, we must train the neurosurgeons of the future in global neurosurgery. 


\section{References}

1. Alkire BC, Raykar NP, Shrime MG, Weiser TG, Bickler SW, Rose JA, et al: Global access to surgical care: a modelling study. Lancet Glob Health 3:e316-e323, 2015

2. Almeida JP, Velásquez C, Karekezi C, Marigil M, Hodaie M, Rutka JT, et al: Global neurosurgery: models for international surgical education and collaboration at one university. Neurosurg Focus 45(4):E5, 2018

3. Brown DW, Einck J, Pawlicki T, Mundt AJ: The case for elective international residency rotations. Int J Radiat Oncol Biol Phys 93:963-964, 2015

4. Davis MC, Rocque BG, Singhal A, Ridder T, Pattisapu JV, Johnston JM Jr: State of global pediatric neurosurgery outreach: survey by the International Education Subcommittee. J Neurosurg Pediatr 20:204-210, 2017

5. Dempsey RJ: Editorial. Global neurosurgery: the role of the individual neurosurgeon, the Foundation for International Education in Neurological Surgery, and "service through education" to address worldwide need. Neurosurg Focus 45(4):E19, 2018

6. Dewan MC, Baticulon RE, Rattani A, Johnston JM, Warf BC, Harkness W: Pediatric neurosurgical workforce, access to care, equipment and training needs worldwide. Neurosurg Focus 45(4):E13, 2018

7. Drain PK, Holmes KK, Skeff KM, Hall TL, Gardner P: Global health training and international clinical rotations during residency: current status, needs, and opportunities. Acad Med 84:320-325, 2009

8. El Khamlichi A: African neurosurgery: current situation, priorities, and needs. Neurosurgery 48:1344-1347, 2001

9. Fallah PN, Bernstein M: Barriers to participation in global surgery academic collaborations, and possible solutions: a qualitative study. J Neurosurg 130:1157-1165, 2019

10. Farmer PE, Kim JY: Surgery and global health: a view from beyond the OR. World J Surg 32:533-536, 2008

11. Ferrada P, Ivatury RR, Spain DA, Davis KA, Aboutanos $\mathrm{M}$, Fildes JJ, et al: International rotations: a valuable source to supplement operative experience for acute-care surgery, trauma, and surgical critical care fellows. J Trauma Acute Care Surg 82:51-57, 2017

12. Henry JA, Groen RS, Price RR, Nwomeh BC, Kingham TP, Hardy MA, et al: The benefits of international rotations to resource-limited settings for U.S. surgery residents. Surgery 153:445-454, 2013

13. Jarman BT, Cogbill TH, Kitowski NJ: Development of an international elective in a general surgery residency. J Surg Educ 66:222-224, 2009

14. Jayaraman SP, Ayzengart AL, Goetz LH, Ozgediz D, Farmer DL: Global health in general surgery residency: a national survey. J Am Coll Surg 208:426-433, 2009

15. Mackay DR: Obtaining Accreditation Council for Graduate Medical Education approval for international rotations during plastic surgery residency training. J Craniofac Surg 26:1086-1087, 2015

16. Meara JG, Greenberg SLM: The Lancet Commission on Global Surgery Global Surgery 2030: evidence and solutions for achieving health, welfare and economic development. Surgery 157:834-835, 2015
17. Mukhopadhyay S, Punchak M, Rattani A, Hung YC, Dahm J, Faruque S, et al: The global neurosurgical workforce: a mixed-methods assessment of density and growth. J Neurosurg 130:1142-1148, 2019

18. Oliphant JL, Ruhlandt RR, Sherman SR, Schlatter MG, Green JA: Do international rotations make surgical residents more resource-efficient? A preliminary study. J Surg Educ 69:311-319, 2012

19. Powell AC, Casey K, Liewehr DJ, Hayanga A, James TA, Cherr GS: Results of a national survey of surgical resident interest in international experience, electives, and volunteerism. J Am Coll Surg 208:304-312, 2009

20. Shah AH, Barthélemy E, Lafortune Y, Gernsback J, Henry A, Green B, et al: Bridging the gap: creating a self-sustaining neurosurgical residency program in Haiti. Neurosurg Focus 45(4):E4, 2018

21. Shultz PA, Kamal RN, Daniels AH, DiGiovanni CW, Akelman E: International health electives in orthopaedic surgery residency training. J Bone Joint Surg Am 97:e15, 2015

22. Sobral FA, Bowder AN, Smith L, Ravipati A, Suh MK, Are C: Current status of international experiences in general surgery residency programs in the United States. Springerplus 5:586, 2016

23. West JL, Fargen KM, Hsu W, Branch CL, Couture DE: A review of Big Data analytics and potential for implementation in the delivery of global neurosurgery. Neurosurg Focus 45(4):E16, 2018

24. World Bank. List of Economies. Washington, DC: World Bank, 2019 (https://databank.worldbank.org) [accessed January 19,2020]

\section{Disclosures}

Dr. Woodrow: consultant for Stryker Spine.

\section{Author Contributions}

Conception and design: all authors. Acquisition of data: Lundy, Miller. Analysis and interpretation of data: all authors. Drafting the article: all authors. Critically revising the article: all authors. Reviewed submitted version of manuscript: all authors. Approved the final version of the manuscript on behalf of all authors:

Lundy. Study supervision: Woodrow.

\section{Supplemental Information \\ Online-Only Content}

Supplemental material is available online.

Supplemental Resident Survey. https://thejns.org/doi/suppl/ 10.3171/2019.12.FOCUS19808.

\section{Correspondence}

Paige Lundy: University of Kansas Hospital, Kansas City, KS. plundy@kumc.edu. 